\title{
Bitter Fennel Fruit Oil
}

National Cancer Institute

\section{Source}

National Cancer Institute. Bitter Fennel Fruit Oil. NCI Thesaurus. Code C107273.

The oil extracted from the fruit of Foeniculum vulgare. Bitter fennel fruit oil can be used as treatment for digestive complaints. 